\title{
The incidence of acute myocardial infarction in relation to overweight and obesity: a meta-analysis
}

Jun Zhu, Xiaohua Su, Gang Li, Jingsong Chen, Bing Tang, Yongjian Yang

Department of Cardiology, General Hospital of PLA, Chengdu Military Area Command, Tianhui Town, Jinniu District, Chengdu, China

Submitted: 19 November 2013

Accepted: 10 February 2014

Arch Med Sci 2014; 10, 5: 855-862

DOI: 10.5114/aoms.2014.46206

Copyright $\odot 2014$ Termedia \& Banach

\section{Abstract}

Introduction: Epidemiological evidence suggests that overweight and obesity have been associated with acute myocardial infarction (AMI). However, data on this issue are controversial. This study aims to use meta-analysis to determine whether overweight and obesity are related to AMI.

Material and methods: We searched PubMed and Embase databases up to October $23^{\text {rd }}, 2013$ for related literature. The association of overweight and obesity with AMI was assessed by odd ratio (OR) with $95 \%$ confidence interval $(\mathrm{Cl})$ as the effect size. Then subgroup analysis was performed according to gender, area and study type.

Results: Five primary studies (one cohort study and four case-control studies) were included in this meta-analysis involving 36803 participants, 14883 of whom had an AMI. There was a significant association between overweight and $\mathrm{AMI}(\mathrm{OR}=1.27,95 \% \mathrm{Cl}: 1.21-1.33, p<0.001)$. Similar results revealed a relation between obesity and $\mathrm{AMI}(\mathrm{OR}=1.22,95 \% \mathrm{Cl}: 1.07-1.40, p=0.003)$. Subgroup analysis showed that overweight and obesity were positively associated with AMI risk except for obese subjects in Europe. There was no publication bias (Begg's test $p=0.972$, Egger's test $p=0.858$ ).

Conclusions: Both overweight and obesity increased the incidence of AMI, and it is necessary to control weight to prevent AMI. A large number of studies is needed to explore the mechanisms that link overweight and obesity with AMI.

Key words: meta-analysis, acute myocardial infarction, overweight, obesity.

\section{Introduction}

Acute myocardial infarction (AMI) is a common disease that could lead to high mortality. In 2006, the WHO reported that 7,200,000 people died of ischemic heart disease with AMI as the major contributor $[1,2]$. The AMI is fatal and often occurs in the prime of life, which brings a heavy burden for individuals and families. The risk factors of smoking, cholesterol, diabetes, obesity, left ventricular hypertrophy, and elevated triglycerides are high in AMI $[3,4]$. These findings would be meaningful for preventing AMI.

In recent years, obesity and overweight have raised more and more concerns. The incidence of overweight and obesity is increasing and has been reported to be associated with type II diabetes mellitus, metabolic syndrome, cancer, hypertension and cardiovascular disease [5-8]. But the

\author{
Corresponding author: \\ Bing Tang MD, \\ Yongjian Yang MD \\ Department of Cardiology \\ General Hospital of PLA \\ Chengdu Military \\ Area Command \\ Rongdu Road 270 \\ Tianhui Town, Jinniu District \\ Chengdu 610083, China \\ Phone: +86028 86570341 \\ Fax: +86 02886570329 \\ E-mail: bingtang2013@ \\ hotmail.com
}


relation of overweight and obesity with AMI is still controversial. Overweight and obesity are associated with AMI in some studies [9-11] and another study also showed an independent relationship between them [12]. Besides, evidence whether overweight and obesity are risk factors for $\mathrm{AMI}$ is still inconsistent. Mehta et al. demonstrated that the risk for mortality is lower in obese patients with $\mathrm{AMI}$ than patients with normal body mass index (BMI) [13]. In Dhoot's study, the mortality of patients with obesity was lower than those not obese [14]. In contrast, Yusuf et al. demonstrated that abdominal obesity increased the risk of AMI in both ages and sexes in all regions [15].

The present literature on the relation of overweight and obesity with $\mathrm{AMI}$ could not confirm obvious conclusions and there is no report about a meta-analysis on their association. In this study, a meta-analysis allowing pooling of data was used to evaluate whether overweight and obesity are risk factors of AMI. Five studies were selected for the meta-analysis. The area of the studies included Portugal, Spain, Italy, Argentina [9, 10, 12, 16, 17]. Besides, subgroup analysis was performed according to gender, geographical area and study type, and publication bias analysis was subsequently performed.

\section{Material and methods}

\section{Search strategy}

We searched PubMed and Embase databases for publications which were updated on October $23^{\text {rd }}, 2013$. The search strategy was ("acute myocardial infarction" or "AMI") and ("BMI" or "body mass index" or "overweight" or "obesity"). We also retrieved articles in paper version by manual searching. Reviews and reference lists of retrieved articles were also reviewed.

\section{Inclusion and exclusion criteria}

The prospective studies in our meta-analysis should meet these inclusion criteria: (1) subjects were adults ( $\geq 18$ years) without AMI; (2) risk factors were overweight or obese; (3) BMI was a predictor of overweight and obesity; (4) outcome of subjects was AMI or death; (5) providing adjusted $\mathrm{RR} / \mathrm{OR}$ (relative risk/odd risk) and $95 \% \mathrm{Cl}$ (confidence intervals) of AMI or they could be calculated according to given data.

Case-control studies had to meet criteria as follows: (1) patients were adults ( $\geq 18$ years) with AMI for the first time; (2) participants in the control group were adults without AMI; (3) providing adjusted RR/OR and $95 \% \mathrm{Cl}$ of $\mathrm{AMI}$ or they could be calculated according to given data.

Exclusion criteria were (1) non-English literature; (2) reviews, letters and comments; (3) repeat publications or multiple publications that reported the same or overlapping population information (studies with the longest follow-up and/or sufficient information were selected).

\section{Data extraction and quality assessment}

Two investigators independently performed the literature screening according to above criteria and then extracted the information according to standardized form. The extract information should include: name of first author and publication year; geographical area; methods; age and gender of patients; number of cases and follow-up (cohort study); sample numbers in disease group and control group; adjusted RR/OR and $95 \% \mathrm{Cl}$; adjustment factors. Then they exchanged the standardized form and solved the differences with discussion.

The Newcastle-Ottawa Scale [18], which includes strict criteria for the case-control group and cohort study, was used in our study to assess the quality of studies. The highest score is 9 and the score of a study with high quality was not less than 7.

\section{Statistical analysis}

Stata 11.0 (Stata Corporation, College Station, Texas) was used for the meta-analysis. Pooled estimates were calculated by averaging the RR/OR and $95 \% \mathrm{Cl}$ based on a random or fixed effects model depending on heterogeneity.

We used Cochrane $Q$ and $R$ for the heterogeneity test [19]. There was heterogeneity among studies when $p<0.05$ and/or ${ }^{2} \geq 50 \%$ and the random effects model was used for pooling estimates. If there was no heterogeneity among studies ( $p \geq 0.05$ and/or $l^{2}<50 \%$ ), the fixed effects model was used for pooling estimates.

Subgroup analysis was performed according to gender, geographical area, study type and so on. Begg [20] and Egger [21] tests were used for publication bias assessment.

\section{Results}

\section{Literature search}

Figure 1 presents the details of the literature search in a flow diagram. We identified 2008 and 900 studies from Embase and PubMed databases respectively based on the search strategy. Then we excluded 2512 duplicated articles and 2489 articles based on titles and abstracts. Then 19 articles were excluded after a full-text review: 4 reviews, 3 non-English articles, 6 studies which lacked a control group; 2 meeting abstracts and 4 articles which are not about the relation between $\mathrm{BMI}$ and $\mathrm{AMI}$. We did not find proper articles by manual searching. Finally, 5 studies including 1 
cohort study and 4 case-control studies were selected for further meta-analysis $[9,10,12,16,17]$.

\section{Study characteristics}

We selected 5 studies in the meta-analysis including 36803 subjects, 14883 of whom had AMI (3 studies in Europe; 1 study included data from 52 countries; 1 study in Argentina). In the four case-control studies, control groups in $3 \mathrm{stu}$ dies were from hospital and 1 study consisted of normal persons. In 2 studies, BMI levels were self-reported. In all 5 studies, subjects had been diagnosed with AMI. In 4 studies, BMI > $25 \mathrm{~kg} /$ $\mathrm{m}^{2}$ was defined as overweight and $\mathrm{BMI}>30 \mathrm{~kg} /$ $\mathrm{m}^{2}$ was defined as obesity. All of the studies were of high quality. Table I shows the details of study baseline characteristics.

\section{Overall analysis}

Figure 2 shows the risk of AMI in the overweight group compared with normal persons. There was no heterogeneity among overweight studies $\left(I^{2}=\right.$ $32.2 \%, p=0.151)$, so the fixed effect model was applied and the results showed that overweight was significantly positively related to $A M I$ (OR = $1.27,95 \% \mathrm{Cl}: 1.21-1.33, p<0.001)$. There was heterogeneity among obesity studies $\left(I^{2}=51.7 \%\right.$, $p=0.043)$, so the random effects model was adopted and the results showed that obesity was significantly positively related to $\mathrm{AMI}(\mathrm{OR}=1.22$, 95\% Cl: 1.07-1.40, $p=0.003$, Figure 3).

\section{Subgroup analysis and publication bias}

Subgroup analysis showed that the results were consistent with previous results except those for obese persons in Europe, which showed a negative correlation with $\mathrm{AMI}(\mathrm{OR}=1.09$, 95\% Cl: 0.80-1.47) (Table II). The results of publication bias were: overweight vs normal, Begg test ( $p=0.972)$, Egger $(p=0.858)$; obesity vs. normal, Begg test $(p=0.978)$, Egger test $(p=1.00)$. The results showed that there was no significant publication bias among studies (data not shown).

\section{Discussion}

Overweight and obesity are increasing problems in many countries and contribute to chronic disease [22], nonalcoholic fatty liver disease [23], inflammatory bowel disease [24], cardiovascular disease [25], heart disease [26] and hypertension [27]. In this study, we evaluated whether overweight and obesity were related to AMI by meta-analysis for the first time. Based on data from 5 studies from prospective cohort and case-control studies, overweight and obesity increased the risk of $\mathrm{AMI}$ compared with normal individuals. Besides, there was no significant publication bias
Search results:

Literature search in Embase (2008)

Literature search in PubMed (900)

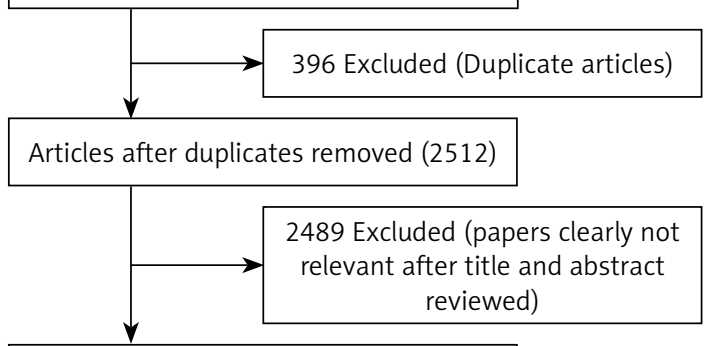

Articles with further reviewed (23)

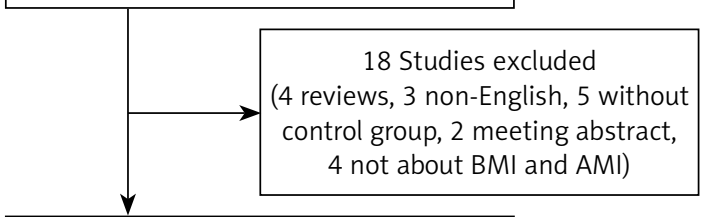

Study included for meta-analysis (5)

Data (18), overweight (10), obesity (8)

Figure 1. Flow diagram of study selection process

among these studies. Confounders such as smoking, hypertension, diabetes and alcohol account for most of the risk of MI worldwide [15]. So they were adjusted to reduce the interference.

In this analysis, although the number of studies is only 5, the sample size is large (36 803 participants; 14883 incident cases of AMI) and included studies were all of high quality. We included both cohort studies and case-control studies to assess whether overweight and obesity are related to AMI to minimize the potential bias. Moreover, we did not only score the included studies but also inclusion and exclusion criteria were established to ensure the minimum quality. We assessed the study through representativeness, ascertainment of exposure, outcomes, follow-up time and other criteria (see Supplementary Table I). The metaanalysis results showed that both overweight and obesity increased the risk of AMI. Several reports were consistent with our results. Schargrodsky et al. demonstrated that overweight is an independent risk factor for MI [12]. The metabolic syndrome including abdominal obesity increased 2-fold in cardiovascular outcomes and 1.5-fold in all-cause mortality [28]. Overweight and obesity independently increased the risk of cardiovascular disease in patients with type 2 diabetes [29]. Yatsuya et al. found that both overweight and obesity increased the risk of cerebral infarction and hemorrhage in men and women [30]. In Strazzullo's study, overweight/obesity was associated with increased risk of ischemic stroke [31]. However, other studies led to the opposite conclusions. Park et al. found that low BMI was associated with increased risks of major cardiovascular events and 


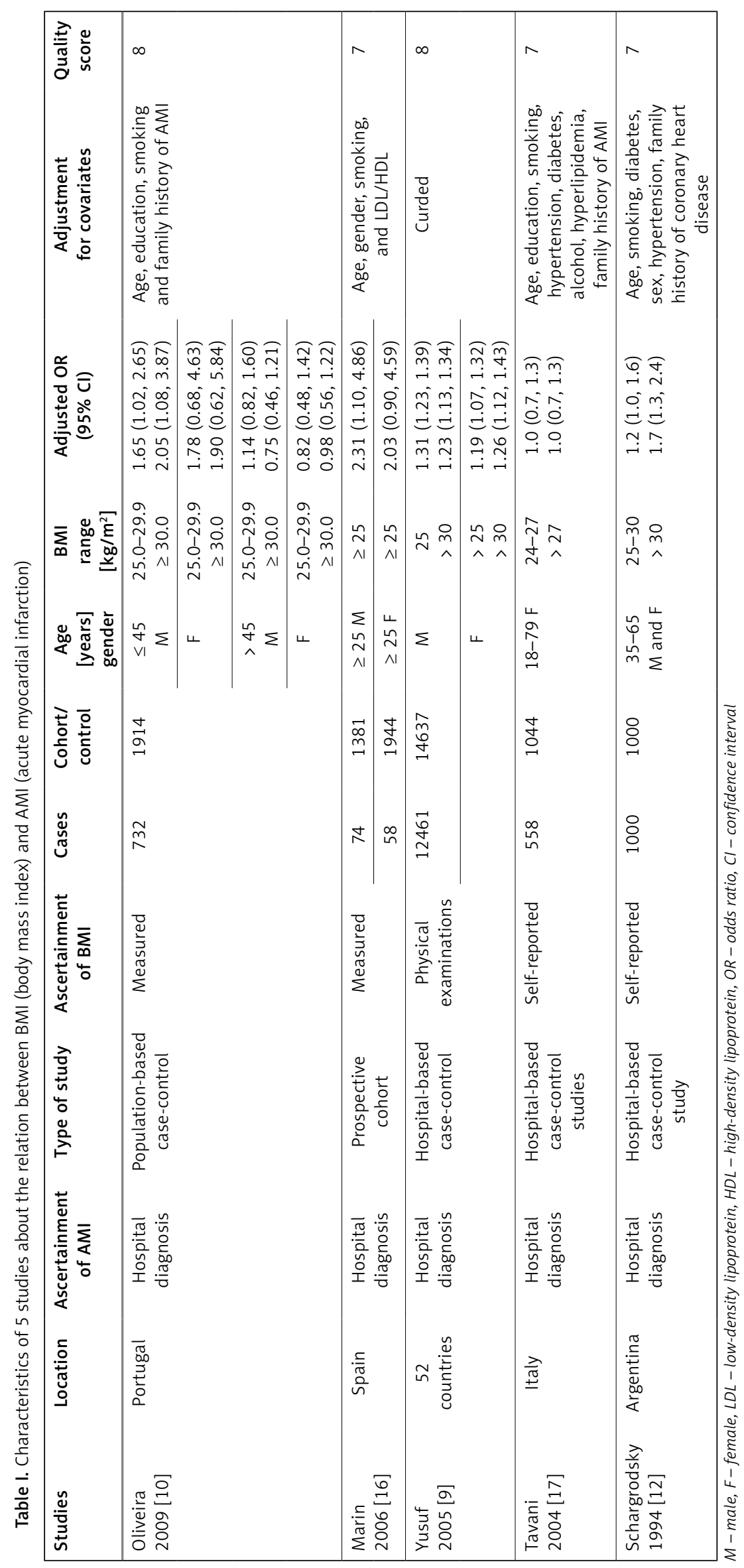




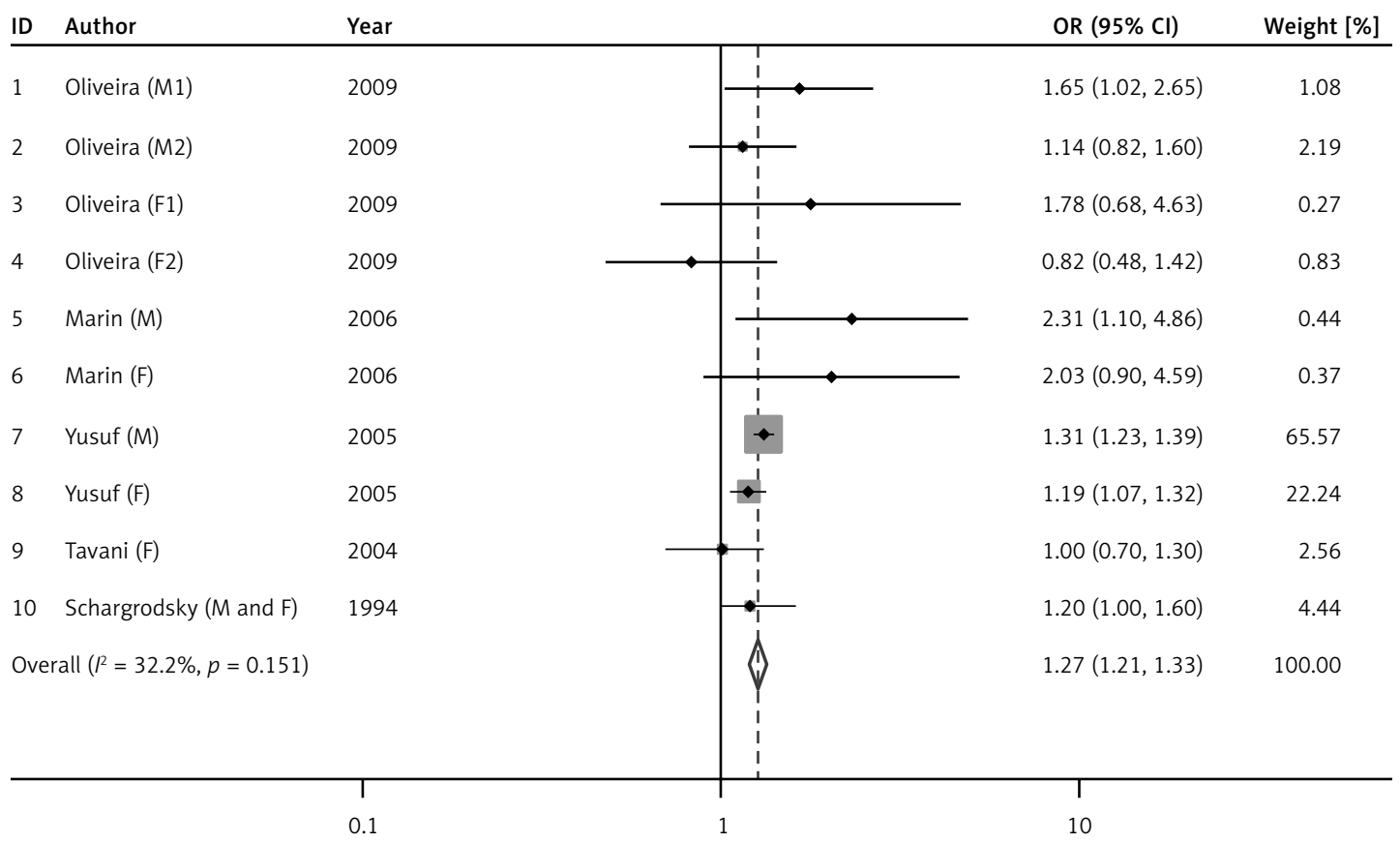

Figure 2. Odds ratio (OR) for the association between overweight and acute myocardial infarction (AMI). Squares represent study-specific relative risk estimates (size of the square reflects the study-specific statistical weight); horizontal lines represent $95 \% \mathrm{Cl}$ (confidence interval); diamonds represent summary relative risk estimates with corresponding $95 \% \mathrm{Cl}$

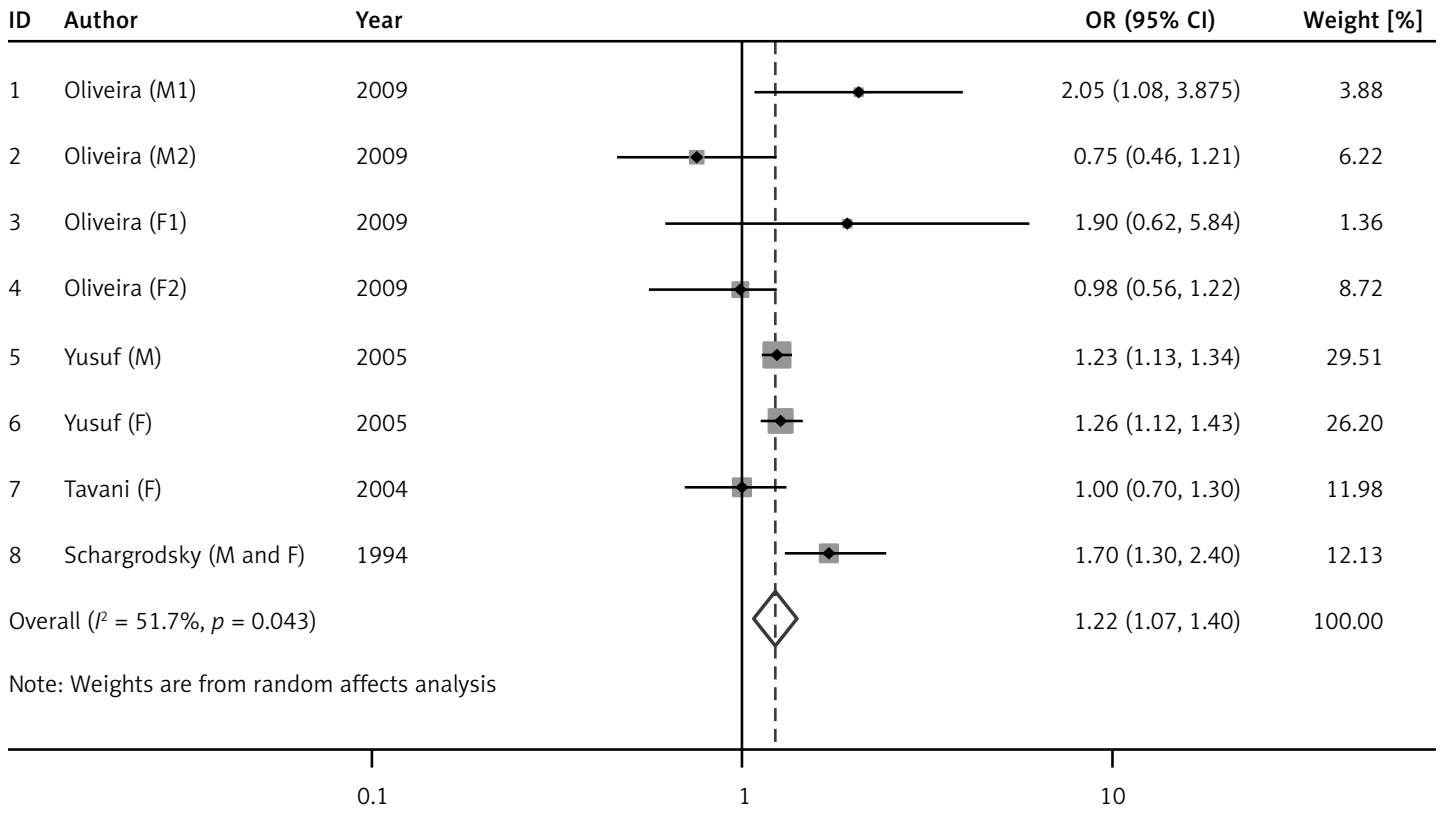

Figure 3. Odds ratio (OR) for the association between obesity and acute myocardial infarction (AMI). Squares represent study-specific relative risk estimates (size of the square reflects the study-specific statistical weight); horizontal lines represent $95 \% \mathrm{Cl}$ (confidence interval); diamonds represent summary relative risk estimates with corresponding $95 \% \mathrm{Cl}$

death among patients who underwent percutaneous coronary intervention [32]. Among overweight and obese older patients after non-ST-segment-elevation myocardial infarction, all-cause long-term mortality was lower than among those with normal weight [33]. There are some explanations for the paradoxical results. First, waist-to-hip ratio not $\mathrm{BMI}$ showed a more significant association with
MI risk [9]. Maybe some unmeasured factors influence the low BMI. Second, the patients who had higher BMI tended to have higher rates of medication use at 12 months after percutaneous coronary intervention [34]. Third, overweight seems to be protective in older populations, but the association is reversed in younger cohorts, indicating that the relation is likely age dependent $[35,36]$. 
Table II. Subgroup analysis of relation between overweight/obesity and AMI (acute myocardial infarction)

\begin{tabular}{|c|c|c|c|c|c|}
\hline \multirow[t]{2}{*}{ Group } & \multirow[t]{2}{*}{ No. of studies } & \multirow[t]{2}{*}{ OR $(95 \% \mathrm{Cl})$} & \multicolumn{2}{|c|}{ Heterogeneity test } & \multirow{2}{*}{$\begin{array}{l}\text { Significance test } \\
(p)\end{array}$} \\
\hline & & & $p$ & $I^{2}(\%)$ & \\
\hline \multicolumn{6}{|l|}{ Overweight: } \\
\hline All studies & 10 & $1.27(1.21,1.33)$ & 0.151 & 32.2 & $<0.001$ \\
\hline \multicolumn{6}{|l|}{ Area: } \\
\hline Europe & 7 & $1.21(1.01,1.44)$ & 0.114 & 41.5 & 0.039 \\
\hline 52 countries & 2 & $1.28(1.21,1.35)$ & 0.121 & 58.4 & $<0.001$ \\
\hline Argentina & 1 & $1.20(1.00,1.60)$ & - & - & 0.128 \\
\hline \multicolumn{6}{|c|}{ Type of research: } \\
\hline Cohort & 2 & $2.18(1.26,3.77)$ & 0.818 & 0.0 & 0.005 \\
\hline Case-control & 8 & $1.26(1.20,1.33)$ & 0.221 & 26.1 & $<0.001$ \\
\hline \multicolumn{6}{|l|}{ Gender: } \\
\hline M & 4 & $1.31(1.24,1.39)$ & 0.285 & 20.9 & 0.959 \\
\hline $\mathrm{F}$ & 5 & $1.17(1.06,1.29)$ & 0.264 & 23.5 & 0.001 \\
\hline$M$ and $F$ & 1 & $1.20(1.00,1.60)$ & - & - & 0.621 \\
\hline \multicolumn{6}{|l|}{ Obesity: } \\
\hline All studies & 8 & $1.22(1.07,1.40)$ & 0.043 & 51.7 & 0.003 \\
\hline \multicolumn{6}{|l|}{ Area: } \\
\hline Europe & 5 & $1.09(0.80,1.47)$ & 0.118 & 45.7 & 0.593 \\
\hline 52 countries & 2 & $1.24(1.16,1.33)$ & 0.751 & 0.0 & $<0.001$ \\
\hline Argentina & 1 & $1.70(1.30,2.40)$ & - & - & 0.001 \\
\hline \multicolumn{6}{|l|}{ Gender: } \\
\hline$M$ & 3 & $1.19(0.79,1.80)$ & 0.040 & 69.0 & 0.398 \\
\hline $\mathrm{F}$ & 4 & $1.17(1.01,1.36)$ & 0.305 & 17.2 & 0.041 \\
\hline$M$ and $F$ & 1 & $1.70(1.30,2.40)$ & - & - & 0.001 \\
\hline
\end{tabular}

Considering that the results may be due to different gender, geographical area and study type, we further conducted a subgroup analysis, and the results showed that the different regions could influence the results of this meta-analysis and was one of the sources of heterogeneity in this study.

There were several limitations to this meta-analysis study. First, we only searched PubMed and Embase datasets. Other datasets such as Medline and Cochrane Library databases could also be included. Second, heterogeneity was significant due to diversity in gender and regions in studies. But this was not surprising due to unavoidable variation in populations among studies. Although confounders such as age, education and smoking $[17,37]$ have been adjusted, the relation of obesity and AMI was still affected by other factors. Thus, it is necessary to adjust for more factors which may affect the study analysis. Third, BMI of participants in some studies was calculated according to self-reported height and weight. So bias might have occurred in these studies. It has been reported that there were large differences between measured and self-reported data [38, 39]. Thus, the self-reported data inevitably led to bias in the meta-analysis. Fourth, most of the studies were carried out with non-comprehensive coverage of areas, which were only Europe and South America, and it is necessary to investigate the relation in other populations. Finally, we only included published studies in our meta-analysis. Therefore, although no publication bias was indicated from either Begg's test or Egger's test, publication bias may have occurred.

In conclusion, this meta-analysis of previous studies suggested that overweight and obesity are associated with higher risk of AMI. Overweight and obesity may affect health, and it is necessary to control one's BMI to prevent AMI. However, large primary studies are needed to confirm our results, and mechanisms of the relation need to be explored.

\section{Acknowledgments}

Co-first author: Jun Zhu and Xiaohua Su

\section{References}

1. Organization WH. Geneva: World Health Organization; 2006. Guidelines for the treatment of malaria 2006. 


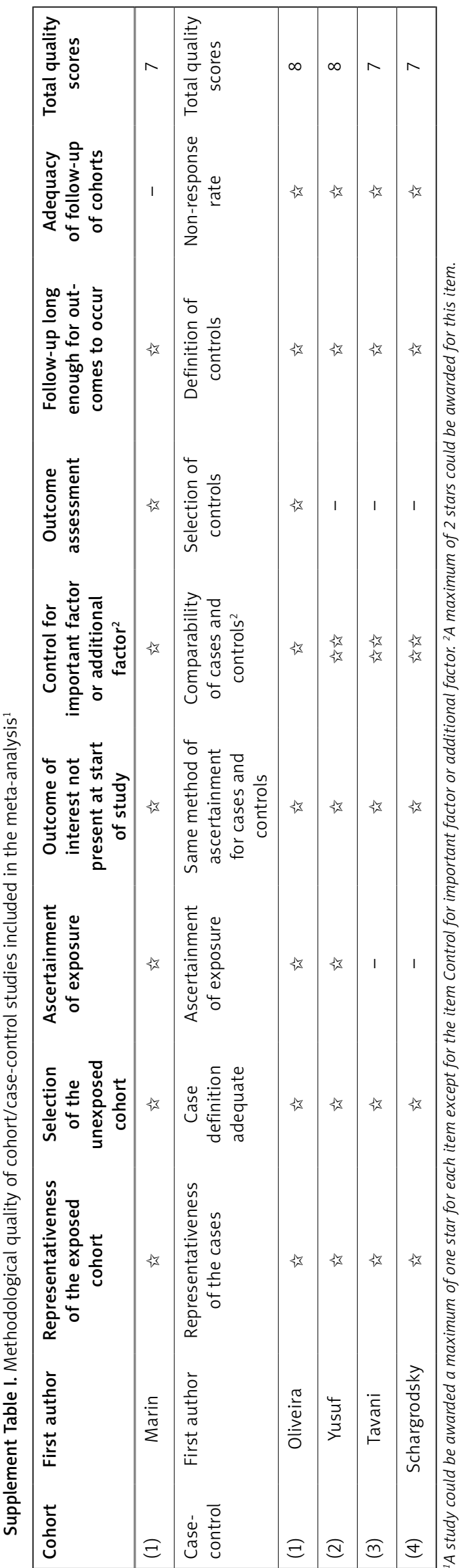

2. Sadowski M, Janion-Sadowska A, Gąsior M, Gierlotka M, Janion M, Poloński L. Higher mortality in women after ST-segment elevation myocardial infarction in very young patients. Arch Med Sci 2013; 9: 427-33.

3. Jonsdottir LS, Sigfusson N, Gunason V, Sigvaldason H, Thorgeirsson G. Do lipids, blood pressure, diabetes, and smoking confer equal risk of myocardial infarction in women as in men? The Reykjavik Study. Eur J Cardiovasc Risk 2002; 9: 67-76.

4. Stampfer MJ, Hu FB, Manson JE, Rimm EB, Willett WC. Primary prevention of coronary heart disease in women through diet and lifestyle. N Engl J Med 2000; 343: 16-22.

5. Tsai AG, Williamson DF, Glick HA. Direct medical cost of overweight and obesity in the USA: a quantitative systematic review. Obes Rev 2011; 12: 50-61.

6. Kelishadi R, Marashinia F, Heshmat R, et al. First report on body image and weight control in a nationally representative sample of a pediatric population in the Middle East and North Africa: the CASPIAN-III study. Arch Med Sci 2013; 9: 210-7.

7. Stępień M, Wlazeł RN, Paradowski M, et al. Serum concentrations of adiponectin, leptin, resistin, ghrelin and insulin and their association with obesity indices in obese normo- and hypertensive patients - pilot study. Arch Med Sci 2012; 8: 431-6.

8. Stępień M, Stępień A, Wlazeł RN, Paradowski M, Banach $M$, Rysz J. Obesity indices and inflammatory markers in obese non-diabetic normo- and hypertensive patients: a comparative pilot study. Lipids Health Dis 2014; 13: 29.

9. Yusuf S, Hawken S, Ounpuu S, et al. Obesity and the risk of myocardial infarction in 27000 participants from 52 countries: a case-control study. Lancet 2005; 366: 1640-49.

10. Oliveira A, Ramos E, Lopes C, Barros H. Self-reporting weight and height: misclassification effect on the risk estimates for acute myocardial infarction. Eur J Public Health 2009; 19: 548-53.

11. Wolk R, Berger P, Lennon RJ, Brilakis ES, Somers VK. Body mass index a risk factor for unstable angina and myocardial infarction in patients with angiographically confirmed coronary artery disease. Circulation 2003; 108: 2206-11.

12. Schargrodsky H, Rozlosnik J, Ciruzzi M, et al. Body weight and nonfatal myocardial infarction in a case-control study from Argentina. Soz Praventivmed 1994; 39: 126-33.

13. Mehta L, Devlin W, Mccullough PA, et al. Impact of body mass index on outcomes after percutaneous coronary intervention in patients with acute myocardial infarction. Am J Cardiol 2007; 99: 906-10.

14. Dhoot J, Tariq S, Erande A, Amin A, Patel P, Malik S. Effect of morbid obesity on in-hospital mortality and coronary rrevascularization outcomes after acute myocardial infarction in the United States. Am J Cardiol 2013; 111: 1104-10.

15. Yusuf S, Hawken S, Ounpuu S, et al. Effect of potentially modifiable risk factors associated with myocardial infarction in 52 countries (the INTERHEART study): case-control study. Lancet 2004; 364: 937-52.

16. Marín A, Medrano MJ, González J, et al. Risk of ischaemic heart disease and acute myocardial infarction in a Spanish population: observational prospective study in a primary-care setting. BMC Public Health 2006; 6: 38.

17. Tavani A, Bertuzzi M, Gallus S, Negri E, La Vecchia C. Risk factors for non-fatal acute myocardial infarction in Italian women. Prev Med 2004; 39: 128-34. 
18. Wells G, Shea B, O'Connell D, et al. The Newcastle-Ottawa Scale (NOS) for assessing the quality of nonrandomised studies in meta-analyses. 2010; Available from: http://www.ohri.ca/programs/clinical_epidemiology/oxford.asp.

19. Higgins JP, Thompson SG, Deeks JJ, Altman DG. Measuring inconsistency in meta-analyses. Br Med J 2003; 327: 557.

20. Begg CB, Mazumdar M. Operating characteristics of a rank correlation test for publication bias. Biometrics 1994: 50: 1088-101.

21. Egger M, Smith GD, Schneider M, Minder C. Bias in metaanalysis detected by a simple, graphical test. Br Med J 1997; 315: 629-34.

22. Must A, Spadano J, Coakley EH, Field AE, Colditz G, Dietz WH. The disease burden associated with overweight and obesity. JAMA 1999; 282: 1523-9.

23. Fabbrini E, Sullivan S, Klein S. Obesity and nonalcoholic fatty liver disease: biochemical, metabolic, and clinical implications. Hepatology 2010; 51: 679-89.

24. Greenblum S, Turnbaugh PJ, Borenstein E. Metagenomic systems biology of the human gut microbiome reveals topological shifts associated with obesity and inflammatory bowel disease. Proc Natl Acad Sci U S A 2012; 109: 594-9.

25. Reddy KS. Cardiovascular disease in non-Western countries. N Engl J Med 2004; 350: 2438-510.

26. Logue J, Murray HM, Welsh P, et al. Obesity is associated with fatal coronary heart disease independently of traditional risk factors and deprivation. Heart 2011; 97: 564-8.

27. Mathieu P, Poirier P, Pibarot P, Lemieux I, Després JP. Visceral obesity the link among inflammation, hypertension, and cardiovascular disease. Hypertension 2009; 53: 577-84.

28. Mottillo S, Filion KB, Genest J, et al. The metabolic syndrome and cardiovascular risk a systematic review and meta-analysis. J Am Coll Cardiol 2010; 56: 1113-32.

29. Eeg-Olofsson K, Cederholm J, Nilsson P, et al. Risk of cardiovascular disease and mortality in overweight and obese patients with type 2 diabetes: an observational study in 13,087 patients. Diabetologia 2009; 52: 65-73.

30. Yatsuya $\mathrm{H}$, Toyoshima $\mathrm{H}$, Yamagishi $\mathrm{K}$, et al. Body mass index and risk of stroke and myocardial infarction in a relatively lean population meta-analysis of 16 Japanese cohorts using individual data. Circ Cardiovasc Qual Outcomes 2010; 3: 498-505.

31. Strazzullo P, D'elia L, Cairella G, Garbagnati F, Cappuccio FP, Scalfi $L$. Excess body weight and incidence of stroke meta-analysis of prospective studies with 2 million participants. Stroke 2010; 41: e418-26.

32. Park DW, Kim YH, Yun SC, et al. Association of body mass index with major cardiovascular events and with mortality after percutaneous coronary intervention. Circ Cardiovasc Interv 2013; 6: 146-53.

33. O'Brien EC, Fosbol EL, Peng SA, Alexander KP, Roe MT, Peterson ED. Association of body mass index and longterm outcomes in older patients with non-ST-segment elevation myocardial infarction results from the CRUSADE Registry. Circ Cardiovasc Qual Outcomes 2014; 7: 102-9.

34. Lancefield T, Clark DJ, Andrianopoulos N, et al. Is there an obesity paradox after percutaneous coronary in tervention in the contemporary era? An analysis from a multicenter Australian registry. JACC Cardiovasc Interv 2010; 3: 660-8.
35. Stevens J, Cai J, Pamuk ER, Williamson DF, Thun MJ, Wood JL. The effect of age on the association between body-mass index and mortality. N Engl J Med 1998; 338: 1-7

36. Bender R, Jöckel KH, Trautner C, Spraul M, Berger M. Effect of age on excess mortality in obesity. JAMA 1999 281: 1498-504.

37. Engström G, Tyden P, Berglund G, Hansen O, Hedblad B, Janzon $\mathrm{L}$. Incidence of myocardial infarction in women. A cohort study of risk factors and modifiers of effect. J Epidemiol Community Health 2000; 54: 104-7.

38. Engstrom JL, Paterson SA, Doherty A, Trabulsi M, Speer KL. Accuracy of self-reported height and weight in women: an integrative review of the literature. J Midwifery Womens Health 2003; 48: 338-45.

39. Gorber SC, Tremblay M, Moher D, Gorber B. A comparison of direct vs. self report measures for assessing height, weight and body mass index: a systematic review. Obes Rev 2007; 8: 307-26. 